\title{
A close association of freedom from pain, migraine-related functional disability, and other outcomes: Results of a post hoc analysis of randomized lasmiditan studies SAMURAI and SPARTAN
}

\author{
Richard B Lipton \\ Yeshiva University Albert Einstein College of Medicine \\ Simin K Baygani \\ Eli Lilly and Company \\ Stewart J Tepper \\ Dartmouth College Geisel School of Medicine \\ John H Krege \\ Eli Lilly and Company \\ Raghavendra Vasudeva \\ Eli Lilly and Company \\ Eric M Pearlman \\ Eli Lilly and Company \\ Paula Hauck \\ Eli Lilly and Company https://orcid.org/0000-0002-2889-235X \\ Li Shen Loo ( $\square$ loo_li_shen@lilly.com ) \\ Eli Lilly and Company
}

\section{Research article}

Keywords: lasmiditan, migraine, efficacy, pain freedom, pain relief, most bothersome symptom (MBS), disability, endpoints

Posted Date: April 5th, 2021

DOI: https://doi.org/10.21203/rs.3.rs-388023/v1

License: @ (1) This work is licensed under a Creative Commons Attribution 4.0 International License. Read Full License 


\section{Abstract}

Background

While pain freedom at $2 \mathrm{~h}$ is a key primary outcome for current trials for acute treatment of migraine, the relationship between the degree of head pain and other efficacy measures at $2 \mathrm{~h}$ has rarely been explored. Following lasmiditan treatment of a migraine attack with moderate or severe head pain, we contrast those who achieve pain freedom with those who achieve mild pain but not pain freedom $2 \mathrm{~h}$ post dosing.

Methods

Patient-level data were pooled across studies and treatment arms from two Phase 3 trials comparing lasmiditan and placebo, SAMURAI and SPARTAN. This post hoc analysis assessed freedom from the most bothersome symptom (MBS), freedom from migraine-related functional disability (disability), and improved patient global impression of change (PGIC) in patients who achieved $2 \mathrm{~h}$ pain freedom compared to those who experienced $2 \mathrm{~h}$ mild pain. Mild pain differs from pain relief which is defined as either mild pain or pain freedom.

Results

Participants who achieved $2 \mathrm{~h}$ pain freedom $(\mathrm{N}=913)$, in comparison with those with $2 \mathrm{~h}$ mild pain $(\mathrm{N}=864)$, were significantly more likely to experience MBS freedom ( $91.9 \%$ vs. $44.9 \%)$, disability freedom ( $87.1 \%$ and $13.4 \%$ ), and improved PGIC ( $86.5 \%$ and $31.5 \%)(p<$ 0.001 for all combinations). In addition, more patients who were pain free experienced both $2 \mathrm{~h}$ MBS freedom and $2 \mathrm{~h}$ functional disability freedom $(83.6 \%)$ compared to those with mild pain $(10.8 \% ; p<0.001)$. The proportion of patients with pain freedom who did not achieve either MBS or disability freedom was lower (4.6\%) than in patients with mild pain (52.4\%). Lastly, $55.2 \%$ of patients experienced mild pain before disability freedom compared to $72.1 \%$ who experienced pain freedom and disability freedom at the same time.

\section{Conclusions}

This study demonstrated that, at $2 \mathrm{~h}$ post treatment, patients who were pain free were more likely to achieve other outcomes including freedom from their MBS, freedom from migraine-related functional disability, and improved PGIC compared to those with mild pain, confirming that $2 \mathrm{~h}$ pain freedom is more robustly associated with other clinical outcomes than the $2 \mathrm{~h}$ mild pain endpoint.

Trial Registration

SAMURAI (NCT02439320); SPARTAN (NCT02605174).

\section{Background}

Previously, the pain-related end point in migraine clinical studies accepted by regulatory bodies was 2-hour pain relief (also called headache response or headache relief); it was defined as a decrease in head pain intensity from moderate or severe at the time of treatment to mild or no pain 2 hours post-dose. (1) The recommended primary end- point for acute treatment of migraine attacks was revised by the International Headache Society (IHS) and Food Drug Administration (FDA) guidelines to pain freedom at 2 hours postdose for the following reasons: 1) placebo rates for pain relief at 2 hours are variable and may exceed 50\%,(1) 2) the pain relief end point defines some patients with incomplete response as achieving success, and 3) judgements about mild pain may be more subjective than judgements about no pain. (2) Thus, the current recommended approach is to assess the effects of acute treatments on pain freedom along with freedom from the patients' self-identified most bothersome symptom (MBS) 2 hours post-dose, chosen from photophobia, phonophobia, or nausea. (3)

The relationship of pain relief and pain freedom to other acute treatment outcomes, including freedom from associated symptoms and disability as well as satisfaction with treatment has not been well explored.

Therefore, we pooled data from the two lasmiditan randomly assigned, controlled, Phase 3 studies, SAMURAI and SPARTAN, to analyze the concordance of clinical efficacy outcomes. Rather than comparing pain relief (which by definition, includes some patients with pain freedom as well as patients with mild pain) with pain freedom, we compared 3 mutually exclusive head pain outcome categories $2 \mathrm{~h}$ 
post treatment (no pain, mild pain, and moderate or severe pain) to determine the relationship of pain outcome with other clinical outcomes at 2 hours post-dose.

\section{Methods \\ Study design}

Pooled patient-level data from double-blind, multicenter Phase 3 trials, SAMURAI (NCT02439320) and SPARTAN (NCT02605174), were included in this post hoc analysis. Details of the original study designs, randomization, and inclusion and exclusion criteria were reported previously. $(4,5)$

The studies adhered to the International Conference on Harmonization Good Clinical Practice guidelines and local regulatory requirements. The protocols were approved by an independent ethics committee or an institutional review board at each study site. Patients provided written informed consent for study participation.

The baseline parameters for inclusion in this analysis were moderate or severe pain, a self-identified MBS (nausea, phonophobia, or photophobia), and some degree of migraine-related functional disability (functional disability).

\section{Efficacy endpoints}

Patients recorded headache pain intensity (none, mild, moderate, or severe) and whether they were experiencing nausea, phonophobia, photophobia, or vomiting at baseline and $0.5,1,1.5,2,3,4,24$, and 48 hours post-dose in an electronic diary.

Patient responses at 2 hours were categorized into three mutually exclusive head pain outcome subgroups: pain freedom (reduction of headache pain severity from moderate or severe at baseline to none); improvement to mild pain (reduction from moderate or severe head pain at baseline to mild); and continued moderate/severe pain.

The pain efficacy outcome responses were compared with other clinically relevant efficacy outcomes of freedom from MBS (defined as the absence of MBS) and freedom from migraine-related functional disability. Functional disability was assessed at all time points using a 4-point ordinal scale with the question "How much is your migraine interfering with your normal activities?". Response options were "not at all", "mild interference", "marked interference", or "need complete bed rest". Functional disability freedom was defined as having "Not at all" recorded. We also assessed patient global impression of change (PGIC). PGIC is an integrated measure of drug tolerability and efficacy that captures the patient's view of improvement or decline in overall well-being after treatment.(6) PGIC was assessed with the question "How do you feel after taking study medication?" with responses recorded using a 7-point Likert scale, ranging from "very much better" to "very much worse". Patients who reported "much better" or "very much better" were considered to have improved with treatment.

\section{Statistical analyses}

All outcome combination and sequence assessments were evaluated using individual patient data. Patient-level data were pooled across studies and treatment arms (50 mg [SPARTAN only], $100 \mathrm{mg}, 200 \mathrm{mg}$ lasmiditan, and placebo)and analyzed by treatment groups. The modified intent-to-treat (mITT) population was used and included patients who took the randomly assigned treatment within 4 hours of migraine onset and provided post-treatment data on headache severity or symptoms. Outcomes reported through 2 hours post-dose were included in this analysis; patients were considered to fail outcomes at each time point if they used rescue medication at or before that time point.

For comparisons between outcome combinations, p-values were computed from a two-sided test from a logistic regression model with study, head pain outcome group, and background use of medication to reduce the frequency of migraine attacks as covariates. Firth's penalized likelihood approach was used to address potential population separation and small sample modelling concerns. Odd ratios were calculated only in cases with sufficient patients $(\geq 10)$ to yield reasonable estimates. A p-value of $<0.05$ was considered to indicate a statistically significant difference.

We analyzed the associations between outcome pairs (outcome A and outcome B) in a 2-by-2 matrix. The odds of two positive outcomes (outcome A-positive and outcome B-positive) in an outcome pair was tested using a Cochran-Mantel-Haenszel test with stratification by study. 
For the subset of patients who achieved both a successful pain outcome and MBS freedom or functional disability freedom at 2 hours, we examined the order of occurrence for those outcomes: outcome A before outcome B, or outcome B before outcome $A$, or both outcomes at the same assessment time point. The numerators were the number of patients within each category defined by order of outcome occurrence, and the denominator was the number of patients who experienced dual outcome by 2 hours post-dose. Participants were indicated as unsustained if they moved into and then out of the dual positive outcome group within the interval from dosing to 2 hours post-dose.

\section{Results}

\section{Patient demographics and baseline characteristics}

The pooled study sample included 913 individuals who were pain free, 864 individuals who improved to mild pain, and 1,052 individuals with moderate or severe pain 2-hours after treatment. Patient demographics were generally similar across the 2-hour head pain outcome groups. A higher proportion of patients in the group that continued to have moderate/severe pain used migraine preventive medications, had severe headache pain, and required complete bed rest at baseline (Tables 1-2).

Table 1

Patient baseline demographics by head pain outcome group at 2 hours post-dose

\begin{tabular}{|c|c|c|c|}
\hline Parameter & $\begin{array}{l}\text { Pain } \\
\text { freedom } \\
(N=913)\end{array}$ & $\begin{array}{l}\text { Improved to mild pain }(\mathrm{N} \\
=864)\end{array}$ & $\begin{array}{l}\text { Continued moderate/severe pain } \\
(\mathrm{N}=1052)\end{array}$ \\
\hline Age, mean (SD) & $\begin{array}{l}41.9 \\
(12.9)\end{array}$ & $41.8(12.1)$ & $42.6(11.8)$ \\
\hline Female, n (\%) & $780(85.4)$ & $745(86.2)$ & $885(84.1)$ \\
\hline White, n (\%) & $711(78.0)$ & $734(85.0)$ & $908(86.3)$ \\
\hline Body mass index, mean (SD) & $30.3(7.8)$ & $30.4(10.6)$ & $29.9(7.8)$ \\
\hline Family history of coronary artery disease, n (\%) & $277(30.3)$ & $251(29.1)$ & $346(32.9)$ \\
\hline Duration of migraine history years, mean (SD) & $\begin{array}{l}17.2 \\
(12.6)\end{array}$ & $19.0(12.8)$ & $20.0(12.8)$ \\
\hline $\begin{array}{l}\text { Average migraine attacks/month in past } 3 \\
\text { months, mean (SD) }\end{array}$ & $5.1(1.6)$ & $5.2(1.9)$ & $5.4(2.1)$ \\
\hline Use of migraine preventive medication ${ }^{\mathrm{a}}, \mathrm{n}(\%)$ & $155(17.0)$ & $186(21.5)$ & $252(24.0)$ \\
\hline \multicolumn{4}{|c|}{$\begin{array}{l}\text { a Based on the question "Is the subject currently using medications to reduce the frequency of migraine episodes?" asked during } \\
\text { randomization. }\end{array}$} \\
\hline \multicolumn{4}{|c|}{$\begin{array}{l}\text { Notes: Data represent the total population (all treatment arms combined). } \mathrm{N}=\text { number of patients in the analysis population with } 2- \\
\text { hour pain response. }\end{array}$} \\
\hline SD: standard deviation. & & & \\
\hline
\end{tabular}


Table 2

Baseline migraine characteristics by head pain outcome group at 2 hours post-dose

\begin{tabular}{|c|c|c|c|}
\hline Baseline migraine characteristic & $\begin{array}{l}\text { Pain } \\
\text { freedom } \\
(\mathrm{N}=913)\end{array}$ & $\begin{array}{l}\text { Improved to mild pain }(\mathrm{N}= \\
864)\end{array}$ & $\begin{array}{l}\text { Continued moderate/severe pain }(\mathrm{N}= \\
1052)\end{array}$ \\
\hline Time to dosing hours, mean (SD) & $1.0(1.7)$ & $1.29(1.69)$ & $1.25(1.56)$ \\
\hline Pain severity, n (\%) & $230(25.2)$ & $170(19.7)$ & $390(37.1)$ \\
\hline Severe & $683(74.8)$ & $694(80.3)$ & $662(62.9)$ \\
\hline \multicolumn{4}{|l|}{ Moderate } \\
\hline Migraine-associated symptoms, n (\%) & 726 (79.5) & $713(82.5)$ & 903 (85.8) \\
\hline Photophobia & $600(65.7)$ & $576(66.7)$ & 740 (70.3) \\
\hline Phonophobia & $384(42.1)$ & $395(45.7)$ & $556(52.9)$ \\
\hline \multicolumn{4}{|l|}{ Nausea } \\
\hline \multirow{2}{*}{$\begin{array}{l}\text { Migraine-related functional disability }{ }^{\mathrm{a}}, \mathrm{n} \\
(\%)\end{array}$} & $131(14.3)$ & $112(13.0)$ & $245(23.3)$ \\
\hline & $489(53.6)$ & $521(60.3)$ & $612(58.2)$ \\
\hline Need complete bed rest & $293(32.1)$ & $231(26.7)$ & 195 (18.5) \\
\hline \multicolumn{4}{|l|}{ Marked interference } \\
\hline \multicolumn{4}{|l|}{ Mild interference } \\
\hline \multicolumn{4}{|c|}{$\begin{array}{l}\text { a Functional disability was assessed with the question "How much is your migraine interfering with your normal activities?". } \\
\text { Response options were "not at all", "mild interference", "marked interference”, or "need complete bed rest". }\end{array}$} \\
\hline \multicolumn{4}{|c|}{ Notes: Data represent the total population (all treatment arms combined). } \\
\hline SD: standard deviation. & & & \\
\hline
\end{tabular}

Concordance of pain outcomes with freedom from MBS, freedom from functional disability, and improved PGIC at 2 hours

At 2 hours, most patients with pain freedom ( $\mathrm{N}=913)$ also experienced MBS freedom (91.9\%) or functional disability freedom (87.1\%). In contrast, patients with mild pain $(\mathrm{N}=864)$, or continued moderate/severe pain $(\mathrm{N}=1,052)$ showed lower rates of MBS freedom (44.9\% and $10.3 \%$, respectively; $p<0.001$ vs group with pain freedom for both) or functional disability freedom (13.4\% and $1.1 \%$, respectively; $p<0.001$ for both). Similarly, most patients (86.5\%) who experienced pain freedom also reported improved PGIC compared to patients with mild pain or moderate/severe pain (31.5\% and 1.7\%, respectively; $p<0.001$ for both) (Table 3 ). 
Table 3

Coexistence of positive outcome(s) with head pain outcome at 2 hours

\begin{tabular}{|c|c|c|c|c|}
\hline \multicolumn{2}{|c|}{ Proportion with additional outcomes at $2 \mathrm{~h}$} & \multirow{2}{*}{$\begin{array}{l}\text { Pain } \\
\text { freedom } \\
\left(\begin{array}{l}N= \\
913)\end{array}\right.\end{array}$} & \multirow{2}{*}{$\begin{array}{l}\text { Improved to mild } \\
\text { pain }(N=864)\end{array}$} & \multirow{2}{*}{$\begin{array}{l}\text { Continued } \\
\text { moderate/ } \\
\text { severe pain ( } \mathrm{N} \\
=1052 \text { ) }\end{array}$} \\
\hline $\begin{array}{l}\text { Number of } \\
\text { outcomes }\end{array}$ & Outcome(s) & & & \\
\hline \multirow[t]{3}{*}{1} & MBS freedom, n (\%) & $\begin{array}{l}839 \\
(91.9)\end{array}$ & $388(44.9) \star$ & $108(10.3)^{\star}$ \\
\hline & Functional disability freedom ${ }^{\mathrm{a}}, \mathrm{n}(\%)$ & $\begin{array}{l}795 \\
(87.1)\end{array}$ & $116(13.4) *$ & $12(1.1)^{\star}$ \\
\hline & PGIC (much better/very much better) ${ }^{\mathrm{b}}, \mathrm{n}(\%)$ & $\begin{array}{l}790 \\
(86.5)\end{array}$ & $272(31.5) \star$ & $18(1.7)^{*}$ \\
\hline 2 & Both MBS freedom and disability freedom ${ }^{\mathrm{a}}, \mathrm{n}(\%)$ & $\begin{array}{l}763 \\
(83.6)\end{array}$ & $93(10.8)^{\star}$ & $3(0.3)$ \\
\hline 3 & $\begin{array}{l}\text { MBS freedom, disability freedom }{ }^{\mathrm{a}} \text {, and PGIC (much } \\
\text { better/very much better) }{ }^{\mathrm{b}}, \mathrm{n}(\%)\end{array}$ & $\begin{array}{l}683 \\
(74.8)\end{array}$ & $64(7.4)^{*}$ & $2(0.2)$ \\
\hline \multicolumn{2}{|c|}{ Neither MBS nor disability freedoma achieved, n (\%) } & $42(4.6)$ & $453(52.4)^{\star}$ & $935(88.9) *$ \\
\hline \multicolumn{2}{|c|}{$\begin{array}{l}\text { Neither MBS freedom, disability freedom }{ }^{a} \text {, nor PGIC (much better/very } \\
\text { much better) }{ }^{b} \text { achieved, } n(\%)\end{array}$} & $16(1.8)$ & $356(41.2) *$ & $925(87.9) *$ \\
\hline
\end{tabular}

${ }^{*} \mathrm{p}<0.001$ versus group with pain freedom at 2 hours. P-values were only calculated from odds ratios if the number of patients in each specific category was $\geq 10$.

a Functional disability was assessed with the question "How much is your migraine interfering with your normal activities?" Response options were "not at all", "mild interference", "marked interference", or "need complete bed rest". Functional disability freedom was defined as having "Not at all" recorded at 2 hours. Patients who recorded "Not at all" at the time of dosing were excluded from the analysis.

b PGIC was assessed with the question "How do you feel after taking study medication?" with responses recorded using a 7-point Likert scale, ranging from "very much better" to "very much worse". Patients who reported "much better" or "very much better" were considered to have improved with treatment.

Notes: Data represent the total population (all treatment arms combined). p-values were generated from a two-sided test from a logistic regression model with study, head pain outcome group, and background use of medication to reduce the frequency of migraine as covariates. Firth's penalized likelihood approach was used to address issues of quasi-complete separation.

MBS: most bothersome symptom; PGIC: patient global impression of change.

The likelihood of patients experiencing two or more positive outcomes, from among MBS freedom, functional disability freedom or improved PGIC, for each of the head pain outcome groups was also examined. Patients with pain freedom at 2 hours experienced both MBS freedom and functional disability freedom outcomes together more frequently (83.6\%) compared to those with mild pain (10.8\%; $p<0.001)$ or continued moderate/severe pain $(0.3 \%)$. Furthermore, patients were much more likely to experience all three positive outcomes (MBS freedom, functional disability freedom, and improved PGIC) if they experienced pain freedom (74.8\%) than if the pain improved to mild $(7.4 \% ; p<0.001)$ or if the pain continued to be moderate/severe $(0.2 \%)$. As expected, very few patients experienced pain freedom without achieving MBS freedom or functional disability freedom (4.6\%, compared to mild pain or continued moderate/severe pain in $52.4 \%$ and $88.9 \%$, respectively; $p<0.001$ ) (Table 3 ). For patients who achieved freedom from MBS at 2 hours, $62.8 \%(839 / 1335)$ were also pain free; this finding contrasts with $29.1 \%$ (388/1335) with mild pain and $8.1 \%(108 / 1335)$ with continued moderate/severe pain (Table 3). Similarly, in patients who experienced freedom from functional disability at 2 hours postdose, the proportion of patients who were also pain free was higher $(86.1 \%, 795 / 923)$ than the proportion of patients who improved to mild pain $(12.6 \%, 116 / 923)$ (Table 3$)$. While lasmiditan-treated patients were more likely to achieve pain freedom than placebo-treated patients, among those who were pain free, the portions with successful outcomes on other endpoints were similar between patients who received lasmiditan versus placebo (Table 4). 
Table 4

Proportion of patients with additional outcomes at 2 hours by treatment and head pain groups.

\begin{tabular}{|c|c|c|c|c|c|c|c|c|c|c|c|c|}
\hline & \multicolumn{3}{|c|}{ Placebo } & \multicolumn{3}{|c|}{ Lasmiditan 50 mg } & \multicolumn{3}{|c|}{ Lasmiditan 100 mg } & \multicolumn{3}{|c|}{ Lasmiditan 200 mg } \\
\hline & PF & MP & $\mathrm{CM} / \mathrm{S}$ & PF & MP & $\mathrm{CM} / \mathrm{S}$ & $\mathrm{PF}$ & MP & CM/S & PF & MP & CM/S \\
\hline Outcome(s) & $\begin{array}{l}N= \\
180\end{array}$ & $\begin{array}{l}N= \\
239\end{array}$ & $\begin{array}{l}N= \\
414\end{array}$ & $\begin{array}{l}N= \\
135\end{array}$ & $\begin{array}{l}N= \\
138\end{array}$ & $\begin{array}{l}N= \\
160\end{array}$ & $\begin{array}{l}N= \\
274\end{array}$ & $\begin{array}{l}N= \\
267\end{array}$ & $\begin{array}{l}N= \\
243\end{array}$ & $\begin{array}{l}N= \\
324\end{array}$ & $\begin{array}{l}N= \\
220\end{array}$ & $\begin{array}{l}N= \\
235\end{array}$ \\
\hline $\begin{array}{l}\text { MBS } \\
\text { freedom, } n \\
(\%)\end{array}$ & $\begin{array}{l}168 \\
(93.3)\end{array}$ & $\begin{array}{l}98 \\
(41.0) *\end{array}$ & $\begin{array}{l}42 \\
(10.1) *\end{array}$ & $\begin{array}{l}126 \\
(93.3)\end{array}$ & $\begin{array}{l}60 \\
(43.5) *\end{array}$ & $\begin{array}{l}19 \\
(11.9)^{*}\end{array}$ & $\begin{array}{l}249 \\
(90.9)\end{array}$ & $\begin{array}{l}131 \\
(49.1) *\end{array}$ & $\begin{array}{l}23 \\
(9.5) *\end{array}$ & $\begin{array}{l}296 \\
(91.4)\end{array}$ & $\begin{array}{l}99 \\
(45.0) *\end{array}$ & $\begin{array}{l}24 \\
(10.2) \text { * }\end{array}$ \\
\hline $\begin{array}{l}\text { Functional } \\
\text { disability } \\
\text { freedom }{ }^{\mathrm{a}}, \mathrm{n} \\
(\%)\end{array}$ & $\begin{array}{l}166 \\
(92.2)\end{array}$ & $\begin{array}{l}34 \\
(14.2) \star\end{array}$ & $3(0.7)$ & $\begin{array}{l}124 \\
(91.9)\end{array}$ & $\begin{array}{l}20 \\
(14.5) *\end{array}$ & $1(0.6)$ & $\begin{array}{l}240 \\
(87.6)\end{array}$ & $\begin{array}{l}34 \\
(12.7) *\end{array}$ & $\begin{array}{l}4 \\
(1.6)\end{array}$ & $\begin{array}{l}265 \\
(81.8)\end{array}$ & $\begin{array}{l}28 \\
(12.7) *\end{array}$ & $\begin{array}{l}4 \\
(1.7) 4\end{array}$ \\
\hline $\begin{array}{l}\text { PGIC } \\
\text { (much } \\
\text { better/very } \\
\text { much } \\
\text { better), n } \\
(\%)\end{array}$ & $\begin{array}{l}159 \\
(88.3)\end{array}$ & $\begin{array}{l}65 \\
(27.2) *\end{array}$ & $7(1.7)$ & $\begin{array}{l}117 \\
(86.7)\end{array}$ & $\begin{array}{l}52 \\
(37.7) *\end{array}$ & $2(1.3)$ & $\begin{array}{l}243 \\
(88.7)\end{array}$ & $\begin{array}{l}84 \\
(31.5) *\end{array}$ & $\begin{array}{l}5 \\
(2.1)\end{array}$ & $\begin{array}{l}271 \\
(83.6)\end{array}$ & $\begin{array}{l}71 \\
(32.3) *\end{array}$ & $4(1.7)$ \\
\hline $\begin{array}{l}\text { Both MBS } \\
\text { freedom } \\
\text { and } \\
\text { disability } \\
\text { free }^{a}, \mathrm{n}(\%)\end{array}$ & $\begin{array}{l}161 \\
(89.4)\end{array}$ & $\begin{array}{l}27 \\
(11.3) *\end{array}$ & $1(0.2)$ & $\begin{array}{l}119 \\
(88.1)\end{array}$ & $\begin{array}{l}16 \\
(11.6) *\end{array}$ & $0(0.0)$ & $\begin{array}{l}228 \\
(83.2)\end{array}$ & $\begin{array}{l}28 \\
(10.5) *\end{array}$ & $\begin{array}{l}2 \\
(0.8)\end{array}$ & $\begin{array}{l}255 \\
(78.7)\end{array}$ & $\begin{array}{l}22 \\
(10.0) *\end{array}$ & $0(0.0)$ \\
\hline $\begin{array}{l}\text { MBS } \\
\text { freedom, } \\
\text { disability } \\
\text { freedom }^{\mathrm{a}} \text {, } \\
\text { and PGIC } \\
\text { (much } \\
\text { better/very } \\
\text { much } \\
\text { better), n } \\
(\%)\end{array}$ & $\begin{array}{l}145 \\
(80.6)\end{array}$ & $\begin{array}{l}16 \\
(6.7)^{*}\end{array}$ & $1(0.2)$ & $\begin{array}{l}107 \\
(79.3)\end{array}$ & $\begin{array}{l}13 \\
(9.4) \star\end{array}$ & $0(0.0)$ & $\begin{array}{l}208 \\
(75.9)\end{array}$ & $\begin{array}{l}20 \\
(7.5)^{\star}\end{array}$ & $\begin{array}{l}1 \\
(0.4)\end{array}$ & $\begin{array}{l}223 \\
(68.8)\end{array}$ & $\begin{array}{l}15 \\
(6.8)^{\star}\end{array}$ & $0(0.0)$ \\
\hline \multicolumn{13}{|c|}{$\begin{array}{l}\text { *p }<0.001 \text { vs group with pain freedom at } 2 \text { hours. P-values were only calculated from odds ratios if the number of patients in each } \\
\text { specific category was } \geq 10 \text {. }\end{array}$} \\
\hline \multicolumn{13}{|c|}{$\begin{array}{l}\text { a Functional disability was assessed with the question "How much is your migraine interfering with your normal activities?". } \\
\text { Response options were "not at all", "mild interference", "marked interference", or "need complete bed rest". Functional disability } \\
\text { freedom was defined as having "Not at all" recorded at } 2 \text { hours. Patients who recorded "Not at all" at the time of dosing were } \\
\text { excluded from the analysis. }\end{array}$} \\
\hline \multicolumn{13}{|c|}{$\begin{array}{l}\text { Notes: p-values were generated from a two-sided test from a logistic regression model with study, head pain outcome group, and } \\
\text { background use of medication to reduce the frequency of migraine as covariates. Firth's penalized likelihood approach was used to } \\
\text { address issues of quasi-complete separation. }\end{array}$} \\
\hline
\end{tabular}

We then evaluated the odds of achieving 2-hour MBS freedom or functional disability freedom by head pain outcome groups. Pain outcomes (pain free or mild pain) were independently paired with MBS and disability outcomes. Patients who were pain free at 2 hours were more likely to be MBS free at 2 hours in comparison with those who did not achieve pain freedom (patients with mild, moderate, or severe pain) (odds ratio $=35.5$ ). Patients who had mild pain were more likely to be MBS free than those who continued to have moderate/severe pain (odds ratio $=7.1$ ). Patients who were pain free at 2 hours were more likely to be free of functional disability at 2 hours in comparison with those who did not achieve pain freedom (odds ratio =64.0). Patients who experienced mild pain were also more likely to be free of functional disability than those who continued to have moderate/severe pain (odds ratio $=13.4$ ).

\section{Concurrence of pain outcomes with freedom from MBS and functional disability}


We next explored the relative timing of achievement of outcomes for patients who achieved freedom from pain or mild pain with either freedom from MBS or functional disability at 2 hours. The proportions of patients experiencing the outcomes sequentially or both outcomes at the same assessment time point are shown in Fig. 1. The proportions of patients achieving freedom from MBS and pain freedom or mild pain concurrently were similar (48.0\% for freedom from MBS with freedom from pain and $47.4 \%$ for freedom from MBS with mild pain) (Fig. 1a). In contrast, the majority of patients experienced freedom from functional disability concurrently with freedom from pain ( $72.1 \%$ for pain free vs $35.3 \%$ with mild pain) (Fig. $1 \mathrm{~b}$ ). This result was similar regardless of treatment (Supplementary Fig. 1). Therefore, freedom from functional disability was more frequently concordant with freedom from pain than improvement to mild pain, and this was independent of treatment.

\section{Discussion}

This project assessed the association between freedom from pain or improvement to mild pain with freedom from MBS, freedom from migraine-related functional disability, and overall improvement in a series of post hoc analyses. The main finding was that MBS freedom, functional disability freedom, and improved PGIC were reported significantly more frequently in patients who achieved pain freedom compared to those who reported mild pain. The proportion of patients who experienced all three positive outcomes was approximately ten times higher in patients who achieved pain freedom compared to those with improvement to mild pain. Although pain free rates were higher with lasmiditan than placebo, among those who achieved pain freedom, rates of MBS freedom, functional disability freedom, and improved PGIC were similar across treatment groups. These findings suggest the relationships of pain status to other outcomes at 2 hours is independent of treatment with lasmiditan.

For the subset of patients who achieved both pain freedom at 2 hours and MBS freedom or functional disability freedom at 2 hours, we examined the concurrence of dual positive outcomes at time points at or before 2 hours. Freedom from MBS could be reported concurrently with either pain freedom or with mild pain. Functional disability freedom and pain freedom occurred simultaneously in a high proportion of patients, suggesting a close temporal association of these outcomes. The analysis showed that in the subset of patients with pain freedom and functional disability freedom by 2 hours, the majority $(72.1 \%)$ achieved both outcomes at the same assessment time. Some patients experienced functional disability freedom before achieving pain freedom (20\%) and a smaller fraction reported pain freedom prior to functional disability freedom (7.5\%). These findings indicate that the outcome of pain freedom generally occurs with return to normal function. Similar results were observed in the placebo group, which implies that the observation may be related to disease recovery, whether spontaneous or induced by treatment.

Previous studies (7-12) evaluated qualities most important to patients when assessing the efficacy of an acute treatment of migraine. Rapid onset of complete pain elimination is a priority for patients and is a predictor of satisfaction with acute therapy.(10) Pain relief, in contrast, especially at early time points, consists mainly of reduction to mild head pain rather than pain freedom. Based on analysis of randomly assigned, controlled trials of acute treatments for migraine, including lasmiditan, aspirin, ibuprofen, ergotamine, and triptans (sumatriptan, zolmitriptan, naratriptan, almotriptan, and rizatriptan), mild headache constitutes $90 \%$ of patients with headache relief after 0.5 hours versus $40 \%$ of patients with headache relief at 2 hours. (13) Furthermore, among patients with episodic migraine, insufficient acute treatment effectiveness is associated with a higher risk of new onset chronic migraine within 1 year, (14) and pain freedom was associated with a lower likelihood of and delayed headache recurrence in a study of naratriptan. (15) This current analysis revealed that in comparison with 2-hour mild pain, patients achieving 2-hour pain freedom were more likely to also achieve MBS freedom, return to normal function, and improved PGIC. Thus, these findings provide additional support for the use of head pain freedom at 2 hours as a primary outcome measure of efficacy for acute treatments of migraine.

One analysis suggested that pain relief was associated with decreased migraine-associated disability and that functional ability can be restored before pain freedom. (16) However, pain relief in that study included those with both mild pain and no pain 2 hours postdose. In our analysis, we found that freedom from functional disability was reported before the onset of pain freedom in $20 \%$ of participants. Rates of freedom from functional disability in those with mild pain at 2 hours are modest (13.4\%) compared to those with freedom from pain at 2 hours (87.1\%). Moreover, $72.1 \%$ of patients achieved freedom from pain and disability concurrently versus $35.3 \%$ with mild pain.

Strengths of this post hoc analysis included the large number of patients pooled from two almost identical Phase 3 clinical trials. The results show a large difference between patients achieving pain freedom versus those reporting mild pain that is biologically plausible and unlikely to be a result of chance. The findings were consistent regardless of treatment assignment to active drug versus placebo in these clinical trials. A limitation is that it is unknown whether other acute treatments for migraine could potentially alter the 
relationships among study outcomes. In addition, this analysis examined three levels of pain outcomes (none, mild, or moderate/severe). Certain baseline characteristics were not evenly distributed among the three groups, and it is possible that the migraine attacks experienced in the continued moderate/severe pain group are more difficult to treat than the other groups. Although functional status was evaluated on a 4-point ordinal scale, we evaluated improvement in functional status as a binary outcome.

\section{Conclusion}

Compared with improvement to mild pain, freedom from head pain at 2 hours post-dose was more frequently associated with freedom from MBS, freedom from migraine-related functional disability, and improved PGIC at 2 hours post-dose. Thus, in the acute treatment of migraine, freedom from pain appears to be a more powerful predictor of other clinically important outcomes than improvement to pain relief.

\section{Declarations}

\section{Ethics approval and consent to participate}

The studies adhered to the International Conference on Harmonization Good Clinical Practice guidelines and local regulatory requirements. The protocols were approved by an independent ethics committee or an institutional review board at each study site. Patients provided written informed consent for study participation.

\section{- SAMURAI}

- Biomedical Research Alliance of New York Institutional Review Board (BRANY IRB); IRB\# 00000080

- Thomas Jefferson University; IRB \#00000152

- Chesapeake IRB; IRB\#00000790

- Crescent City IRB

- SPARTAN

- Chesapeake

- Compass IRB

- Ärztekammer Niedersachsen Ethikkommission

- Bayerische Landesärztekammer Ethikkommission

- Ethik-Kommission bei der Landesärztekammer Baden-Württemberg

- Ethik-Kommission der Ärztekammer Westfalen-Lippe und der Medizinischen Fakultät der Westfälischen Wilhelms-Universität München

- Ethikkommission des Fachbereichs Medizin der Ludwig-Maximilians Universität

- Geschäftsstelle der Ethikkommission des Landes Berlin

- Landesamt für Gesundheit und SozialesLandesärztekammer Hessen Ethikkommission

- Sächsische Landesärztekammer Ethikkommission

- London - Bloomsbury Research Ethics Committee

\section{Consent for publication}

Not applicable

\section{Data Sharing statement}

Lilly provides access to all individual participant data collected during the trial, after anonymization, with the exception of pharmacokinetic or genetic data. Data are available to request 6 months after the indication studied has been approved in the US and EU and after primary publication acceptance, whichever is later. No expiration date of data requests is currently set once data are made available. Access is provided after a proposal has been approved by an independent review committee identified for this purpose and after receipt of a signed data sharing agreement. Data and documents, including the study protocol, statistical analysis plan, clinical 
study report, blank or annotated case report forms, will be provided in a secure data sharing environment. For details on submitting a request, see the instructions provided at www.vivli.org.

\section{Competing interests}

RL: - Edwin S. Lowe Professor of Neurology at the Albert Einstein College of Medicine in New York. Receives research support from the $\mathrm{NIH}$, from the Migraine Research Foundation and the National Headache Foundation. Serves on the editorial board of Neurology, senior advisor to Headache, and associate editor to Cephalalgia. Reviewed for the NIA and NINDS, holds stock options in eNeura Therapeutics and Biohaven Holdings; serves as consultant, advisory board member, or has received honoraria from or conducted studies funded by the American Academy of Neurology, Abbvie/Allergan, American Headache Society, Amgen, Biohaven, Dr. Reddy's, Electrocore, Eli Lilly and Company, eNeura Therapeutics, GlaxoSmithKline, Merck, Pernix, Teva, Trigemina, Vector, Vedanta. Receives royalties from Wolff's Headache 7th and 8th Edition, Oxford Press University, 2009, Wiley and Informa.

ST: - Grants for research (no personal compensation): Allergan, Amgen, Dr. Reddy's, ElectroCore, Eli Lilly, eNeura, Lundbeck, Neurolief, Novartis, Satsuma, Scion Neurostim, Teva, Zosano. Consultant and/or Advisory Boards (honoraria): Acorda, Aeon, Alexsa, Align Strategies, Allergan, Alphasights, Amgen, Aperture Venture Partners, Aralez Pharmaceuticals Canada, Axsome Therapeutics, Becker Pharmaceutical Consulting, BioDelivery Sciences International, Biohaven, Charleston Labs, ClearView Helathcare Partners, CoolTech, CRG, Currax, Decision Resources, DeepBench, Eli Lilly, eNeura, Equinox, ExpertConnect, GLG, GSK, Guidepoint Global, Healthcare Consultancy Group, Health Science Communications, Impel, Lundbeck, M3 Global Research, Magellan Rx Management, Marcia Berenson Connected Research and Consulting, Medicxi, Navigant Consulting, Neurolief, Nordic BioTech, Novartis, Pulmatrix, Reckner Healthcare, Relevale, Revance, SAI MedPartners, Satsuma, Scion Neurostim, Slingshot Insights, Sorrento, Spherix Global Insights, Sudler and Hennessey, Synapse Medical Communications, System Analytic, Teva, Theranica, Thought Leader Select, Trinity Partners, Unity HA, XOC, Zosano. Salary: Dartmouth-Hitchcock Medical Center, American Headache Society, Thomas Jefferson University. CME honoraria: American Academy of Neurology, American Headache Society, Cleveland Clinic Foundation, Diamond Headache Clinic, Elsevier, Forefront Collaborative, Hamilton General Hospital, Ontario, Canada, Headache Cooperative of New England, Henry Ford Hospital, Detroit, Inova, Medical Learning Institute Peerview, Medical Education Speakers Network, Miller Medical Communications, North American Center for CME, Physicians' Education Resource, Rockpointe, ScientiaCME, WebMD/Medscape

SKB, JHK, RV, EMP, PMH and LSL, are full-time employees and minor stockholders of Eli Lilly and Company.

\section{Funding}

This study was sponsored Eli Lilly and Company, Indianapolis, Indiana, USA. The SAMURAI and SPARTAN clinical trials, which were the source of the data analyzed, were funded by CoLucid Pharmaceuticals, Inc. CoLucid is a wholly owned subsidiary of Eli Lilly and Company.

\section{Authors'contributions}

RBL, SKB, SJT, JHK, RV, EMP, and LL were involved in study conception and design.

SB performed data analysis.

RBL, SKB, SJT, JHK, RV, EMP, PMH, and LL provided data interpretation.

RBL, SKB, SJT, JHK, RV, EMP, PMH, and LL were involved in drafting/revising the article.

RBL, SKB, SJT, JHK, RV, EMP, PMH, and LL provided final approval of the version to be published.

\section{Acknowledgements}

Not applicable

\section{Authors' information (optional)}

Not applicable 


\section{References}

1. Diener HC, Tassorelli C, Dodick DW, Silberstein SD, Lipton RB, Ashina M, et al. Guidelines of the International Headache Society for controlled trials of acute treatment of migraine attacks in adults: Fourth edition. Cephalalgia. 2019;39(6):687-710.

2. Garcia-Azorin D, Yamani N, Messina LM, Peeters I, Ferrili M, Ovchinnikov D, et al. A PRISMA-compliant systematic review of the endpoints employed to evaluate symptomatic treatments for primary headaches. J Headache Pain. 2018;19(1):90.

3. U.S. Department of Health and Human Services Food and Drug Administration. Migraine: Developing Drugs for Acute Treatment Guidance for Industry https://www.fda.gov/media/89829/download. 2018.

4. Goadsby PJ, Wietecha LA, Dennehy EB, Kuca B, Case MG, Aurora SK, et al. Phase 3 randomized, placebo-controlled, double-blind study of lasmiditan for acute treatment of migraine. Brain. 2019;142(7):1894-904.

5. Kuca B, Silberstein SD, Wietecha L, Berg PH, Dozier G, Lipton RB, et al. Lasmiditan is an effective acute treatment for migraine: A phase 3 randomized study. Neurology. 2018;91(24):e2222-e32.

6. Smith T, Krege JH, Rathmann SS, Dowsett SA, Hake A, Nery ESM, et al. Improvement in Function after Lasmiditan Treatment: Post Hoc Analysis of Data from Phase 3 Studies. Neurol Ther. 2020.

7. Smelt AF, Louter MA, Kies DA, Blom JW, Terwindt GM, van der Heijden GJ, et al. What do patients consider to be the most important outcomes for effectiveness studies on migraine treatment? Results of a Delphi study. PLoS One. 2014;9(6):e98933.

8. Davies GM, Santanello N, Lipton R. Determinants of patient satisfaction with migraine therapy. Cephalalgia. 2000;20(6):554-60.

9. Lanteri-Minet M. What do patients want from their acute migraine therapy? Eur Neurol. 2005;53 Suppl 1:3-9.

10. Lipton RB, Hamelsky SW, Dayno JM. What do patients with migraine want from acute migraine treatment? Headache. 2002;42 Suppl 1:3-9.

11. Lipton RB, Stewart WF. Acute Migraine Therapy: Do Doctors Understand What Patients With Migraine Want From Therapy? Headache: The Journal of Head and Face Pain. 1999;39(s2):S20-S6.

12. Pietrini U, De Luca M, Del Bene E. Endpoints to evaluate efficacy of symptomatic drugs in migraine: what do patients want? Headache. 2002;42(9):948-9.

13. Tfelt-Hansen P, Diener HC. Pain freedom after 2 hours should be the primary outcome in controlled trials treating migraine attacks. Cephalalgia. 2020:333102420941827.

14. Lipton RB, Fanning KM, Serrano D, Reed ML, Cady R, Buse DC. Ineffective acute treatment of episodic migraine is associated with new-onset chronic migraine. Neurology. 2015;84(7):688-95.

15. Sheftell F, O'Quinn S, Watson C, Pait D, Winter P. Low migraine headache recurrence with naratriptan: clinical parameters related to recurrence. Headache. 2000;40(2):103-10.

16. Dodick DW, Lipton RB, Ailani J, Halker Singh RB, Shewale AR, Zhao S, et al. Ubrogepant, an Acute Treatment for Migraine, Improved Patient-Reported Functional Disability and Satisfaction in 2 Single-Attack Phase 3 Randomized Trials, ACHIEVE I and II. Headache. 2020;60(4):686-700.

\section{Figures}


(a) Relative Timing of MBS Freedom

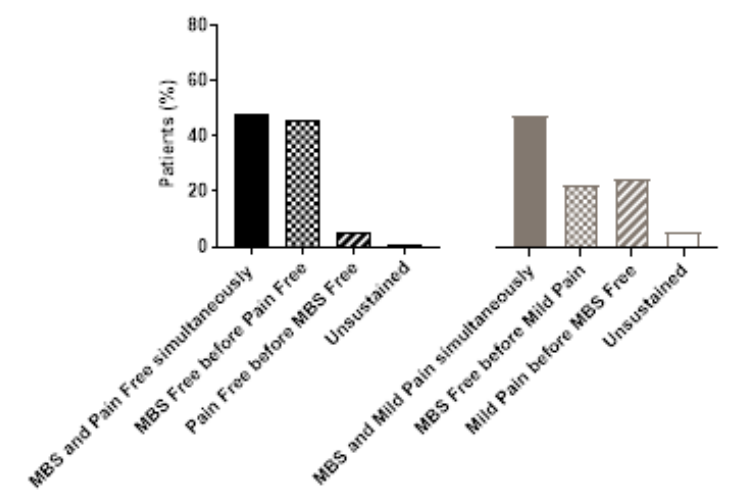

(b) Relative Timing of Functional Disability Freedom

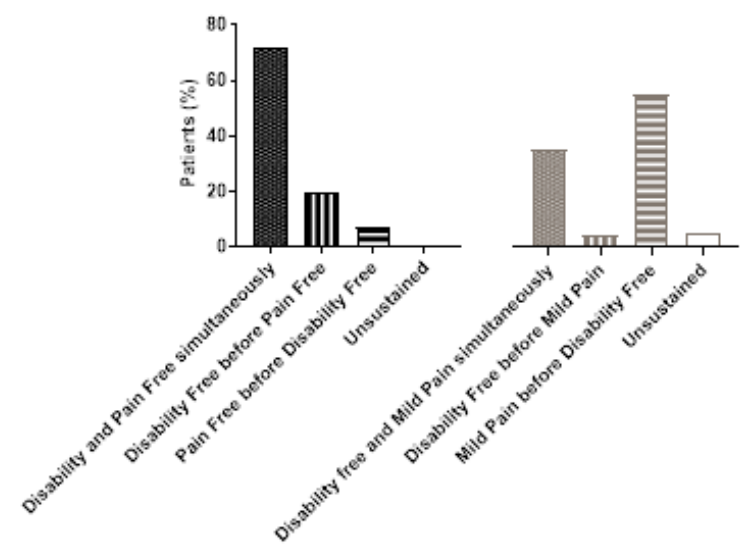

\section{Figure 1}

Relative timing of freedom from most bothersome symptom (MBS) or functional disability and pain status. (a) Sequence of outcomes in patients that experienced MBS freedom and either pain freedom $(\mathrm{N}=839)$ or mild pain $(\mathrm{N}=388)$ at two hours. (b) Sequence of outcomes patients that experienced functional disability freedom and either pain freedom $(N=795)$ or mild pain $(N=116)$ at 2 hours. Notes: Unsustained represented patients who experienced freedom from MBS or functional disability freedom and either freedom from pain or improvement to mild and then moved out of that group prior to 2 hours post-dose. The denominator was the total population that achieved the MBS freedom or disability freedom at 2 hours post-dose in either the pain free or mild pain groups.

\section{Supplementary Files}

This is a list of supplementary files associated with this preprint. Click to download.

- SupplementalFigure1.docx 